\title{
Challenges in Conducting MBBS Program in a Nepalese Medical College
}

\author{
Reddy KR ${ }^{1}$
}

'Professor of Microbiology, Department of Medical Education, Gandaki Medical College \& Teaching Hospital, Pokhara, Nepal

\author{
Keywords \\ Challenges, MBBS program, \\ Medical College, Nepal.

\section{Corresponding author \\ *Dr. K. Rajeshwar Reddy \\ Professsor \& Head \\ Microbiology Department \\ Gandaki Medical College Teaching \\ Hospital, Pokhara, Nepal \\ Email: reddysir4861@gmail.com}

\begin{abstract}
The medical education in Nepal faces many challenges. Medical education, in order to keep up with the times, needs to adapt to the changing attitudes of society. We need a change for better. The curriculum is outdated to the clinical needs, and the students are rarely taught any skills and innovations or creativity to think for the future, and whoever wishes to change the system will be isolated. A serious shortage of talents, subject knowledge, technical skills and communication skills in teachers is affecting the future of medical students. Many medical teachers teach in local language making students poor communicators.
\end{abstract}

Nepal, a developing country in South Asia is in transition had suffered from a decade long violent conflict and the country is in the implementation of its new constitution and suffers from political instability which may contribute several challenges like general shutdowns, frequent bandhs, shortage of electricity, load shedding, voltage fluctuation and problems with internet in conducting MBBS program in a Medical College.

At the moment, there is no foreseeable future effort by parents, teachers, educationists, policy makers and politicians to correct this and courageously bring in radical reforms in medical education. These challenges can be overcome by cooperation and working together to create a peaceful and stable climate. Nepal has been going through tremendous changes in the last few years. Medical teachers have a great role to play and stand against many odds.

\section{INTRODUCTION}

A medical college is a tertiary educational institution or part of such an institution that teaches medicine, and awards a professional degree for physicians and surgeons. In other words, only institutions offering MBBS course in its curriculum are referred to as medical colleges.

Medical education in Nepal started in 1933 when the Nepal Rajakiya Ayurved Vidyalaya opened at Kathmandu for the training of Ayurvedic health workers. A year later, the Civil Medical School was set up at Kathmandu, for the training of basic level health care workers (Compounders and dressers). The Institute of Medicine (IOM) was started in 1972 and began the process of training different basic, middle and higher levels of human resources for health. After the Jana Andolan in 1989/90, health services education in Nepal developed almost by leaps and bounds ${ }^{1}$.

The medical education in Nepal faces many challenges. Medical education, in order to keep up with the times, needs to adapt to the changing attitudes of society. We need a change for better. The curriculum is outdated to the clinical needs, and the students are rarely taught any skills and innovations or creativity to think for the future, and whoever wishes to change the system will be isolated. Medical teachers have a great role to play and stand against many odds. 
A serious shortage of talents, subject knowledge, technical skills and communication skills in teachers is effecting the future of medical students resulting in lack of technical knowledge and critical thinking. Many medical teachers teach in local language making students poor communicators and lack of English proficiency.

Nepal, a developing country in South Asia is in transition had suffered from a decade long violent conflict and the country is in the implementation of its new constitution and suffers from political instability which may contribute several challenges like general shutdowns, frequent bandhs, shortage of electricity, load shedding, voltage fluctuation and problems with internet in conducting MBBS program in a Medical College.

\section{GANDAKI MEDICAL COLLEGE}

Gandaki Medical College Teaching Hospital and Research Center Pvt. Ltd. (GMC) is a health educational institution located at Lekhnath, Kaski District of Nepal, was established in 2007 AD with the aim of imparting high quality medical education to the students from different parts of the world. The emphasis is on developing attitude, skills and habits of life-long learning and to produce the world leaders in medicine. The focus is on the needs of today's medical students and the requirements of tomorrow's doctors in the challenging healthcare environment ${ }^{2}$.

Presently, Gandaki Medical College is conducting MBBS, BDS, B.Sc. Nursing, B.Sc. MIT, B.Sc. MLT and BPH Programs with the affiliation of Tribhuvan University-Institute of Medicine (IOM). The college has been successfully running in its aim of providing high quality medical education and health care services to the people. Gandaki Medical College proposes a 750 bedded teaching hospital with all activity of clinical and medical facilities, to provide excellent health care facilities. The college admitted the first batch of MBBS students in 2010 and has recently admitted the seventh batch of students.

\section{CURRICULUM}

The MBBS (Bachelor of Medicine and Bachelor of Surgery) course is of four and half years duration followed by one year compulsory rotating internship. The college follows the curriculum prescribed by Tribhuvan University Institute of Medicine (IOM). The salient features of the curriculum are emphasis on common health problems of Nepal, early clinical and community exposure with adequate community based learning and integrated approach in teaching and learning ${ }^{3}$.
The MBBS program aims to produce socially responsible physicians, who are willing and able to meet the existing and emerging challenges of national and international healthcare system, and highly competent and scientifically literate clinicians, equipped to practice patient-centred medicine in a constantly changing modern world, with a foundation in the basic medical and social sciences.

On completion of the MBBS course and one year of compulsory rotating internship, the medical graduates must acquire the following core competencies ${ }^{4,5}$.

1. Patient care: Must be able to provide appropriate, compassionate and effective treatment of health problems and the promotion of health.

2. Medical knowledge and skills: Must be able to demonstrate knowledge about established and evolving biomedical, clinical and cognate sciences and the application of this knowledge to patient care. Must understand the clinical relevance of scientific research and demonstrate the ability to evaluate emerging knowledge and research as it applies to diagnosis, treatment and the prevention of disease.

3. Practice-based learning: Must be able to investigate and evaluate and improve their patient care practices

4. Interpersonal communication skills: Must be able to exchange information effectively with patients, and their families, professional associates and society at large.

5. Professionalism: Must demonstrate a commitment to carry out professional responsibilities, adherence to ethical principles and sensitivity to a diverse patient population

6. Systems-based practice: Must understand the interdependence of the component parts of the healthcare system and appropriately use system resources to provide optimal patient care.

Table 1: Curriculum outline and implementation modality in MBBS program

\begin{tabular}{ll}
\hline First Year & $\begin{array}{l}\text { Integrated basic medical science } \\
\text { and community medicine }\end{array}$ \\
Second Year & $\begin{array}{l}\text { Integrated basic medical science } \\
\text { Community medicine (Applied } \\
\text { epidemiology, family health } \\
\text { exercise), forensic medicine, } \\
\text { clinical subjects } \\
\text { Clinical subjects, community } \\
\text { medicine (District health }\end{array}$ \\
Fourth Year & $\begin{array}{l}\text { service management) } \\
\text { Clinical subjects }\end{array}$ \\
Four and half Year & Rotating internship \\
\hline
\end{tabular}




\section{The first phase of MBBS program}

The curriculum is divided into three phases ${ }^{3}$. The first phase is of two years duration and covers the six basic science subjects of anatomy, physiology, biochemistry, pathology, microbiology, and pharmacology along with community medicine in horizontal integrated organ system-based manner. Basic concepts and the musculoskeletal and neurosensory organ systems are taught in the first year and respiratory, cardiovascular, gastrointestinal, renal and electrolyte, endocrine and reproductive systems during the second year. During the first year, community medicine includes epidemiology, biostatistics, sociology, family health, communication skills, information technology, community health laboratory and community health diagnosis.

Students will have community field visit for one month in first year for an early exposure to community based learning. Students visit the hospital for two weeks in second year for early clinical exposure for vertical integrated learning. The emphasis is on history taking, communication skills, and physical examination.

Students are required to have at least $75 \%$ attendance in theory and practical sessions of all the disciplines and also in early clinical exposure to appear in the University examinations of the respective disciplines.

\section{The second phase of MBBS program}

In the second phase, during third year of MBBS program, the teaching includes disciplines of forensic medicine, community medicine (Applied epidemiology, family health exercise), internal medicine, surgery, obstetrics and gynecology and pediatrics.

\section{The third phase of MBBS program}

In the third phase, during fourth year and fifth year (First half year) the teaching is mainly concentrated on the clinical subjects: Internal medicine, surgery, obstetrics and gynecology, pediatrics, ophthalmology, ENT, orthopedics, dentistry, psychiatry, dermatology, radiology, anesthesiology, accident and emergency medicine, community medicine (District health system management) and clinical rotation in major clinical areas. Information technology, ethics and research will be covered during this phase.

\section{SKILLS LAB}

The basic clinical skills will be learnt in clinical skills laboratory. Skills lab will be an important learning resource for students during the period of learning to take histories and examining the patient. Students will learn basic skills of certain clinical examination and performing common medical procedures. The great majority of clinical skills are learnt by seeing the seniors do it multiple times and by slowly doing it oneself. Working in a skill lab will supplement this and is not a substitute for practicing these in the different wards, in accident and emergency and in the surgery in real patients. Students will be posted in skills lab during second year, junior internship and in the beginning of internship.

\section{INTERNSHIP}

During one year of compulsory rotating internship, the interns are rotated across various specialities including internal medicine, general surgery, orthopedics, pediatrics, obstetrics and gynecology, anesthesia, accident and emergency medicine, ophthalmology, ENT etc. Interns obtain hands-on training in the wards and out-patient departments, where they interact with real patients. Besides standard clinical care, the interns also obtain a thorough experience of ward management, staff management, and thorough counseling skills ${ }^{3}$.

\section{TEACHING-LEARNING METHODOLOGY}

The predominant teaching-learning methodology is didactic lectures, but as per the IOM curriculum, Gandaki Medical College is adopting the SPICES model of instructions during the implementation of curriculum as far as possible and practicable ${ }^{3}$.

Table 2: SPICES model of instruction

\section{Student centered}

Problem based

\section{Integrated}

\section{Community oriented}

\section{Electives}

\section{Systematic approach}

Thus, following approaches will be followed while implementing the curriculum ${ }^{3}$ :

- Organ-system based integrated teaching and early clinical and community exposure

- Teaching and learning in rural community settings (community based learning)

- Periodic review of basic medical sciences related to common and important clinical problems 
- Self directed learning to inculcate the habit of lifelong learning

- Problem based learning (PBL)

- Didactic lectures or structured interactive sessions

- Ambulatory teaching in outpatient departments for better exposure and understanding of commonly encountered medical problems

- Bedside teaching learning in wards

- Acquiring certain clinical examination and procedural skills in a skill laboratory

- Demonstrations, role plays, practice on simulated patients wherever applicable

- Presentation of reports on community diagnosis, family health exercise and district health service management

\section{MEDICAL EDUCATION DEPARTMENT}

In order to make the students learn better, Teacher training programs and continuing medical education (CME) programs are conducted periodically to update the knowledge of teachers regarding new advances and new teaching methods to facilitate students' learning. This is usually held for two to three hours in the afternoon session, once in a month, so that the regular academic and clinical activities are not hampered. The CME workshop concentrates on the roles and responsibilities of a medical teacher, principles of learning, educational objectives, teaching-learning aids, communication skills, and microteaching.

\section{ACADEMIC CALENDER}

We prepare a calendar of operation for every academic year (December to November) at the beginning of November (Table 3). The possibility of bandhs, shutdowns and other problems will always be considered while preparing academic calendar. During the last six years we have been able to complete the sessions within the requisite time frame. Two years ago due to blockade we had to shorten the time period allotted. In the first year we set apart a month for the community diagnosis program where students spend in rural areas.

We are conducting theory and practical sessions in a professional manner. We occasionally miss few sessions due to adverse circumstances because of political instability in Nepal. Therefore we ensure sufficient flexibility in the academic program (Teaching schedule) to ensure that days which are lost do not adversely affect the academic calendar.
There are regular meetings of Heads of the departments to discuss academic schedule (Teaching schedule), plan of conducting learning in different organ systems in an integrated manner, correlation seminars etc.

The major challenge is allotting theory and practical classes for different departments so that the curriculum and organ system progresses in an integrated manner. We usually ask each department to give us the number of theory and practical classes they need for a particular organ system so that the required number of classes can be allotted each week.

Respective departments develop their own teaching schedules and calendar of operation for teaching learning activities based on the curriculum guidelines. The curriculum implementation committee reviews, evaluates and monitors teaching methodology.

\section{CORRELATION SEMINARS}

Correlation seminars ${ }^{6}$ are conducted at the end of covering each organ system during the first and second year. For correlation seminar, a common disease or problem involving the organ system just covered is selected. The College holds a meeting of Professors/Heads from each of the basic science departments, community medicine under the chairmanship of Principal for selecting the topics for correlation seminars. Topics are selected based on the importance of the disease condition, its public health relevance, and its ability to integrate learning objectives from the maximum number of subjects. The concerned departments are asked to generate two to six objectives for each seminar topic, if possible.

After learning objectives have been framed, they are distributed to all students. The college admits 110 students to the MBBS course each year. Therefore 110 learning objectives are framed for each correlation seminar and a particular learning objective is assigned to each student. The students prepare a five minute power point presentation of the objective assigned, using the assigned text books, reference books available in the college library, notes from faculty lectures, and help from the faculty members of the relevant departments. Students also use articles and images obtained thr ough Google search.

The evaluation of correlation seminar is done by one faculty member (usually Professor/Head) from each basic science department and one from community medicine. A Senior Professor was entrusted the responsibility of being the team leader and coordinates the proceedings of correlation seminar. 
Table 3: Academic calendar

\section{Gandaki Medical College}

Lekhnath-2, Kaski

Operation/Academic Calendar 2015/16

\begin{tabular}{|c|c|c|c|c|c|c|c|c|c|c|c|c|c|c|c|c|c|c|c|c|c|c|c|c|c|c|c|c|}
\hline S. & \multirow[t]{3}{*}{ Program } & \multicolumn{27}{|c|}{ Month and week } \\
\hline No & & \multicolumn{27}{|c|}{ June } \\
\hline & & 1 & 2 & 3 & 4 & 1 & 2 & 3 & 4 & 1 & 2 & 3 & \begin{tabular}{l|l}
4 & 1
\end{tabular} & 2 & 3 & 4 & 1 & 2 & 3 & 4 & 1 & 2 & 3 & 4 & 1 & 2 & 3 & 4 \\
\hline 1 & $\begin{array}{l}\text { MBBS } \\
1^{\text {st }} \text { year }\end{array}$ & & & $\begin{array}{l}\text { Class } \\
\text { start }\end{array}$ & & & & & & & & & \multirow{2}{*}{\multicolumn{3}{|c|}{\begin{tabular}{l|l}
$\mathbf{S}$ & \multicolumn{1}{|c}{$\mid$} \\
$\mathbf{P}$ & \multicolumn{1}{|c}{} \\
\cline { 2 - 3 } $\mathbf{0}$ & Suppl \\
$\mathbf{R}$ & exam \\
$\mathbf{T}$ & vacation \\
$1^{\text {st }}$ year
\end{tabular}}} & & & & & \multicolumn{2}{|c|}{\begin{tabular}{|l|l}
$1^{\text {st }}$ \\
term \\
exam
\end{tabular}} & & & & & & & CS \\
\hline 2 & $\begin{array}{l}\text { MBBS } \\
2^{\text {nd }} \text { year }\end{array}$ & & & & $\begin{array}{l}\text { Class } \\
\text { start }\end{array}$ & & & & & & & & & & & & & & & \multicolumn{4}{|c|}{\begin{tabular}{l|l} 
CS \& \\
$1^{\text {st }}$ \\
Term \\
exam
\end{tabular}} & & & & CS & \\
\hline 3 & $\begin{array}{l}\text { MBBS } \\
3^{\text {rd }} \text { year }\end{array}$ & & & & & & & & & $\begin{array}{l}\text { Class } \\
\text { start }\end{array}$ & & & $S$ & & & & & & & & & & \multicolumn{3}{|c|}{$\begin{array}{l}\text { Suppl exam } \\
\text { vacation } \\
2^{\text {nd }} \text { year }\end{array}$} & $\begin{array}{l}1^{\text {st }} \text { term } \\
\text { exam } \\
\text { (All) }\end{array}$ & & \\
\hline 4 & $\begin{array}{l}\text { MBBS } \\
4^{\text {th }} \text { year }\end{array}$ & & & & & & & & & & & & $\begin{array}{l}\text { E } \\
\text { E }\end{array}$ & & $\begin{array}{l}\text { Class } \\
\text { start }\end{array}$ & & & & & & & & & & & \multicolumn{2}{|c|}{$\begin{array}{l}\text { Suppl exam } \\
\text { vacation } 3^{\text {rd }} \text { year }\end{array}$} & \\
\hline 5 & $\begin{array}{l}\text { MBBS } \\
5^{\text {th }} \text { year }\end{array}$ & & & & & & & & & & & & $\mathbf{K}$ & & & & & & $\begin{array}{l}\text { Class } \\
\text { start }\end{array}$ & & & & & & $\begin{array}{l}\text { pl exam } \\
\text { ation } \\
\text { year }\end{array}$ & & & \\
\hline
\end{tabular}

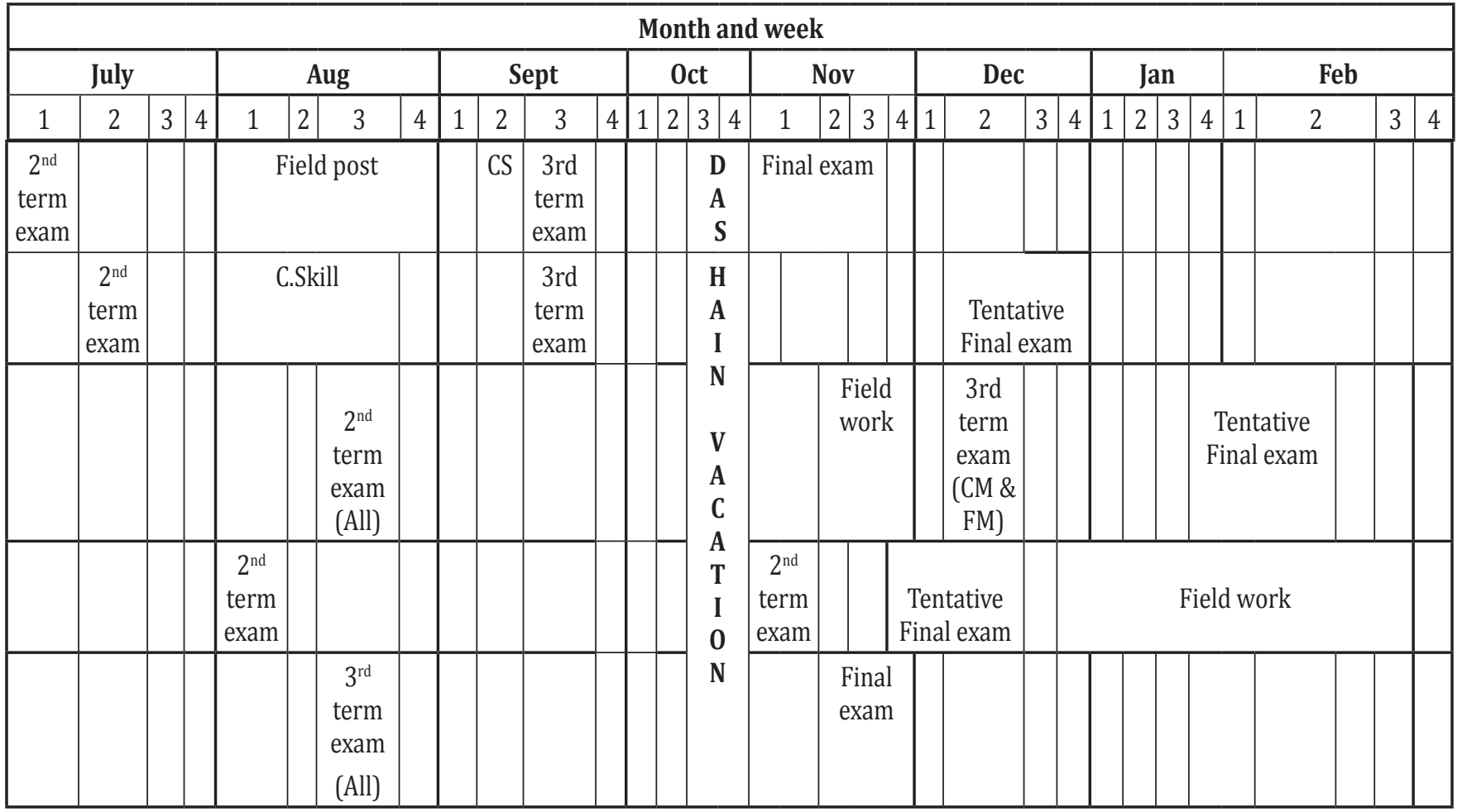

Abbreviations: $\mathrm{CS}=$ Correlation seminar, C.Skill = Communication skills and history taking in Hospital

Note:

1. Operational academic plan subject to change due to strikes, bandhs, TU/IOM schedules

2. Besides term examinations, class tests can be conducted by concerned departments

3. Detail terminal examination schedule will be published by examination section two weeks before

4. Progress report of each term exam will be sent to parents by courier

5. As per the University guidelines, students must have minimum $75 \%$ attendance and $40 \%$ marks in term exams to be eligible to appear in the final University examination 


\section{EXAMINATIONS}

There are regular assessments at the end of every month (monthly tests) and three term examinations (Internal assessments) at the end of each term, and students are counseled to improve their performance. The internal assessments follow the University examination pattern and there are integrated question papers in basic sciences. The total time allotted for integrated basic sciences examination is four hours and the maximum number of marks obtainable is 120 , each basic science subject accounting for 20 marks. Each department is requested to submit their question papers on University pattern about one week before the date of examination. The marks obtained in assessment examinations account for about $20 \%$ of marks during the University examinations.

The University examinations are conducted by the Institute of Medicine (IOM), Tribhuvan University. The theory examinations are based on common question paper and examinations are held at different medical colleges simultaneously with external observers from the University. The practical examinations are conducted in different affiliated colleges with an external examiner and an internal examiner appointed by the University ${ }^{3}$.

At the end of the first year there is an integrated question paper in all basic science subjects and two question papers in community medicine and practical examination in each basic science subject and community medicine separately. At the end of second year there are three integrated question papers in basic science subjects, one question paper in respiratory system and cardiovascular system, the second one in gastrointestinal and hepatobiliary system, and the third question paper is in renal and electrolyte system, and reproductive and endocrine systems; and a practical examination in each basic science subject separately ${ }^{3}$.

The practical examination includes objective structured practical examination (OSPE), clinical case presentation, objective structured clinical examination (OSCE) and other evaluation modalities applicable to the subjects concerned ${ }^{3}$.

\section{COMMUNICATION SKILLS}

Behavioral sciences, ethical issues, information technology and communication skills knowledge have become an essential part of medical education/practice. At Gandaki Medical College, we are providing a communication skills program, to enable the graduates to communicate clearly, sensitively, effectively and efficiently with patients, peers and also with colleagues from a variety of health and social care professions in their clinical and community practice. Good communication enables one to collect information about a patient's problems that is comprehensive, relevant and accurate. It helps medical graduates to make an accurate, comprehensive diagnosis.

\section{COMMUNITY BASED LEARNING}

During the first year of MBBS program, students will have one month community health diagnosis field visit in rural areas of Kaski district studying community health problems and involving the community in solving the health problems that they observe (Table 4). Students observe various determinants of health, prepare a written report and present the same to the community for discussion and action. The determinants could be social, economic and health service-related. Social determinants could be community beliefs about diarrhea like restricting fluid intake during the illness, economic determinants could be poverty and purchasing medicines while health service-related could be problems in accessing health facilities. Students are examined and evaluated in their community health diagnosis project during the community medicine practical examination. Students may go back to the communities during their third and fourth year of MBBS program and follow up on the changes suggested.

Early exposure of the learners to community medicine makes them aware of the importance of the course of the study, and enables them to become motivated towards self-learning. Placement in the community surroundings that are located in the mountain, the hills and the plains of Nepal gives ample opportunities to learners to be accustomed to the reality that exists in the community so that they can face real-life situations after graduation.

During the third year of MBBS program, students will have family health exercise, designed to enable the students to understand the social, cultural, psychological, gender and economical aspects of illness, the interactions of ill persons with different members of family and community health service, role of family members and family environment in patient care to produce competent family physicians. Students will understand the natural history of disease and importance of patient follow up. Students will be able to differentiate the nature of the problems while seeing the patients in the family from the nature of the same problems when the patient is seen in clinic or hospital. 
During the fourth year of MBBS program, students will be posted in the field (District health system management) for nine weeks in small groups by rotation to the various health institutions at the zonal and district levels; three weeks in each Institution. The students will build rapport with different officials of health and other Institutions. They will visit different health service facilities and other relevant Institutions like DDC, VDC, NGOs, INGOs, local groups etc., participate in different activities and interact with different people. The students will collect information from different sources, analyze and interpret them and present at the district to relevant audience.

\section{EARLY CLINICAL EXPOSURE}

We provide early clinical exposure to our students during second year, enabling vertical integrated learning also. The emphasis is on history taking skills, communication skills, and physical examination. The major clinical departments of medicine, surgery, pediatrics, obstetrics and gynecology, ophthalmology, family medicine, orthopedics and otorhinolaryngology (ENT) are involved. Students rotate in batches for fifteen days.

\section{MEDICAL ETHICS}

Healthcare decisions are based not only on clinical and technical grounds, but also on ethical grounds. Through the teaching/learning exercises in this medical ethics module, we aim to instill in the medical students, knowledge, skills and attitudes necessary to guide their conduct and decision making as a practicing doctor. The general aim of this medical ethics module is to help medical students to recognize the importance of being sensitive to ethical issues within everyday clinical practice and develop in them the ability to effectively address ethical concerns of patients as well as participants in research.

\section{INFORMATION MANAGEMENT}

In order to use information and communication technology to assist in diagnostic, therapeutic and preventive measures and for surveillance and monitoring health status, and also to maintain records of patients for future use and medico-legal purpose, we provide a brief training to our medical graduates.

\section{CONCLUSIONS}

We conduct regular meetings to discuss and plan teaching schedules, plan of conducting teaching learning process in different organ systems, correlation seminars, academic calendar etc. The challenges we face in running the MBBS program are general shutdowns, frequent bandhs, shortage of electricity, load sheding, voltage fluctuation and problems with internet and political instability. Therefore we prepare a very flexible academic schedule and try to adjust the sessions wherever possible. We are fully committed to conduct the community health diagnosis residential field to enable the students to have a community based learning and also early clinical exposure. These challenges can be overcome by various factors (political and nonpolitical) and working together in cooperation and creating a peaceful and stable political climate.

As medical teachers and educationists we should strive to develop the innate talent of future doctors that can help them do better in life, get their creative juices flowing and contribute to the society. Teachers should encourage multiplicity of ideas, richness of thought and acceptance of differing view point. We teachers must allow minds to flower, not atrophy.

The medical education system must give students the courage to question what they learn, infer from intelligent reasoning and become thinking individuals. One definite way is to stimulate their minds and reasoning by throwing ideas at them, so that they will be forced to think, analyze and comprehend. 


\section{REFERENCES}

1. Dixit H. Development of medical education in Nepal. Kathmandu University Medical Journal. 2009; 7(1): Issue 25, 8-10.

2. Gandaki Medical College Teaching Hospital \& Research Centre Pvt. Ltd. http://www.gmc.edu.np

3. Medical education Department, Tribhuvan University Institute of Medicine. Curriculum for Bachelor of Medicine and Bachelor of Surgery (MBBS). Kathmandu, Nepal: Tribhuvan University Institute of Medicine. 2008.

4. Nepal Medical Council. http://www.nmc.org.np
5. Tuladhar TM. Milestones of Nepal medical council in medical education in Nepal. Nepal Medical Council/ Nepal Medical Association. 1995.

6. Reddy KR. Correlation seminars in basic sciences at Gandaki Medical College, Lekhnath, Kaski, Nepal. Journal of Gandaki Medical College-Nepal. 2016; 9(1): 57-61.

7. Marahatta SB, Sinha NP, Dixit H, Shrestha IB, Pokharel PK. Comparative study of community medicine practice in MBBS curriculum of health institutions of Nepal. Kathmandu University Medical Journal. 2009; 7(4) Issue 28: 461-469. 